\title{
Prevalence and factors associated with postpartum depression during the COVID- 19 pandemic among women in Guangzhou, China: a cross-sectional study
}

Peiqin Liang ${ }^{1}$, Yiding Wang ${ }^{1}$, Si Shi ${ }^{1}$, Yan Liu ${ }^{1 *}$ and Ribo Xiong ${ }^{2^{*}}$ (I)

\begin{abstract}
Background: The 2019 coronavirus disease (COVID-19) is a public health emergency of international concern. To date, there are limited studies that have investigated the impact of COVID-19 pandemic on mental health among female population. Therefore, the study aims to investigate the prevalence of postpartum depression (PPD) and it's related factors among women in Guangzhou, China, during the COVID-19 pandemic.
\end{abstract}

Methods: A cross-sectional study was performed from 30th March 2020 to 13th April 2020 using anonymous online questionnaire among 864 women at 6-12 weeks postpartum. The Chinese version of Edinburgh Postnatal Depression Scale and a questionnaire regarding associated factors were administered to all participants. Multivariate logistic regression was used to determine factors that were significantly associated with PPD.

Results: The prevalence of PPD among women at 6-12 weeks postpartum was 30.0\%. A multivariate logistic regression model identified significant factors as: immigrant women, persistent fever, poor social support, concerns about contracting COVID-19 and certain precautionary measures.

Conclusions: The findings suggest the need for policies and interventions to not only mitigate the psychological impacts but also target disadvantaged sub-groups of women following childbirth during the COVID-19 pandemic.

Keywords: Coronavirus, Postpartum depression, Epidemic, Risk factors, China

\section{Background}

The 2019 coronavirus disease (COVID-19) is a highly infectious disease and have posed a global health threat [1]. Since the emergence of COVID-19 infection in Wuhan, China on December 2019, it has rapidly spread across China and other countries around the world [2]. On January 30th 2020, the World Health Organization (WHO) declared the outbreak of the COVID-19 as a

\footnotetext{
*Correspondence: 19714343@qq.com; xiongribo@outlook.com

'Department of gynecology \&obstetrics, The Third Affiliated Hospital of Southern Medical University, 183\#West Zhongshan Avenue, Guangzhou, Guangdong province, China

2Department of rehabilitation, Nanhai Hospital, Southern Medical University, 28\#liguan Road, Lishui County, Foshan City, Guangdong Province, China
}

public health emergency of international concern [3]. Since the outbreak, the Chinese government has taken a swift move to reduce the spread of the virus. As of 19th March, zero domestic infection was recorded for the first time since it's outbreak in China [4].

The ongoing COVID-19 pandemic is not only threatening people's physical health but also inducing fear and helplessness. Previous research has explored such psychological effect during the outbreaks of infection [5-7]. During the Severe Acute Respiratory Syndrome (SARS) outbreak, $17.3 \%$ of heath workers had experienced mental symptoms [5]. During one influenza break, around $10 \sim 30 \%$ of general population were concerned about

(C) The Author(s). 2020 Open Access This article is licensed under a Creative Commons Attribution 4.0 International License, which permits use, sharing, adaptation, distribution and reproduction in any medium or format, as long as you give appropriate credit to the original author(s) and the source, provide a link to the Creative Commons licence, and indicate if changes were made. The images or other third party material in this article are included in the article's Creative Commons licence, unless indicated otherwise in a credit line to the material. If material is not included in the article's Creative Commons licence and your intended use is not permitted by statutory regulation or exceeds the permitted use, you will need to obtain permission directly from the copyright holder. To view a copy of this licence, visit http://creativecommons.org/licenses/by/4.0/ The Creative Commons Public Domain Dedication waiver (http://creativecommons.org/publicdomain/zero/1.0/) applies to the data made available in this article, unless otherwise stated in a credit line to the data. 
the possibility of contracting the disease [6]. Similarly, the impacts of COVID-19 pandemic on mental health including depression and negative assessment have also been recorded [7]. Risk factors such as being female, student status, specific physical symptoms, poor self-rated health status and increased self-blame were associated with a higher risk of COVID-19-related post-traumatic stress symptoms [7]. For women, the transition to motherhood is a challenging period and has been considered a window of increased vulnerability for the development of mental illness [8]. Therefore, it's essential to understand the potential psychological changes caused by COVID-19 among perinatal women.

During the postpartum period, women are vulnerable to clinical depression characterized by depressed mood, agitation, disappointment and sleep disorders [9]. Prior research has identified a number of biological, psychological, socioeconomic, and cultural factors that were associated with the development of postpartum depression (PPD) [8]. For example, women with limited financial means are more prone to report PPD [10], perhaps due to the increased financial stress to raise an infant. During the COVID-19 pandemic, it's imperative to understand the complex interplay of these factors in the development of PPD in Chinese context. Affected by COVID-19, people behave in a more reticent and conservative way such as staying at home with family and reducing get-togethers with friends and relatives [11]. It indicated that people were more likely to gain more support from their family members during this period. On the other hand, restricted travel policy and self-isolation regulations may lead to a more passive lifestyle and a subsequent worsened mental health. To date, there're limited studies that have investigated the impact of COVID-19 pandemic on mental health of women after delivery.

This study aims to investigate the prevalence of PPD among women in Guangzhou, China, and to explore the related factors of PPD during the COVID-19 pandemic.

\section{Methods}

This study was conducted in Guangzhou, the capital city of Guangdong province and one of the largest metroplis in south China. The city of Guangzhou had a population of more than 16 million, $50 \%$ of which were internal migrants [12]. Patients were recruited from the obstetrics unit in the Third Affiliated Hospital of Southern Medical University, a 1000-bed tertiary teaching hospital in Guangzhou, China. In 2019, annual delivery in this unit reached about 4000 .

A cross-sectional study was carried out from 30th March 2020 to 13th April 2020 in our hospital using anonymous online questionnaire. The sample size was determined on the assumed effect size of 0.30 , referring the study of Gaskin, et al. [13] To obtain reasonable estimates at $95 \%$ confidence level and 5\% margin of error, a total sample size of 367 was needed. We recruited women at 6-12 weeks after childbirth, 1) Chinese nationality; 2) be living in Guangzhou, China over a month during the COVID-19 period. The COVID-19 period refers to the period from January 2020 until April 2020; 3) providing informed consent in the online questionnaire. Women who had a history or family history of psychiatric disorders were excluded. Women who returned incomplete questionnaires were also excluded. A total of 887 candidates were invited to participate; 23 women refused to be enrolled in and 19 women returned incomplete questionnaire, resulting 845 eligible women. This study included 845 women, allowing detection of significant differences with a power of 0.88 calculated by GPower software.

Data were collected using an anonymous structured questionnaire. The Chinese version of Edinburgh Postnatal Depression Scale (EPDS) was employed to assess PPD with a threshold of 10 . The sensitivity and specificity of Chinese version have been found to be 0.82 and 0.86 respectively which were comparable to the original scale [14]. Women with a score of 10 or more were then experienced severity evaluation using Hamilton Depression Rating Scale for depression. A score of $\geq 7, \geq 17$ and $\geq 24$ were used to identify mild, moderate and severe depression respectively [15].

The questionnaire was based on literature [8] and reviewed by experts in obstetrics and epidemiology from our university. The questionnaire was consisted of the following information: 1) socio-demographic characteristics such as age, employment, annual household income, and household registration place; 2) obstetric data and physical symptoms, such as parity, mode of delivery, pregnancy associated diseases, delivery associated diseases, fever, cough, sore throat, as well as persistent fever and cough or difficulty in breathing; 3) social profiles such as perceived family income sufficiency, family socio-economic status, social support and marital relationship. 4) concerns about COVID-19, such as level of confidence in diagnosis, likelihood of self and other family members contracting COVID-19 and likelihood of surviving if infected; 5) precautionary measures against COVID-19, such as avoidance of sharing of utensils (e.g., chopsticks) during meals, covering mouth when coughing and sneezing, and the average number of hours staying at home per day to avoid COVID-19. Social support was measured by Likert scale, an instrument composed of three subscales that can be classified into informational support, emotional support and household activity support. It's reliability and validity have been confirmed in a previous study [16]. As the Chinese government recommended the public to isolate themselves at home, women were asked to complete an online questionnaire 
through an online survey platform. The data collection phase was completed with the help of six nurses and 4 post-graduates. They were trained for one afternoon by the principal investigator covering quality control, completeness of information and research ethics. All completed questionnaires were checked for completeness and consistency.

Ethics approval was obtained from the Research Ethics Board of Southern Medical University.

The primary data was entered into Epidata 3.0 before being exported to SPSS16.0. Chi-square test (for qualitative data) or Student's $t$ test (for quantitative data) was used to assess the differences in socio-demographic characteristics, obstetric data and physical symptoms, social profiles and COVID-19-related factors between women who had PPD and those who did not. The independent variables that were significantly associated $(P<$ 0.05 ) with PPD were considered as possible contributing factors and entered into a multivariate logistic regression model. The model controlled for household registration in Guangzhou, persistent fever, social support, likelihood of contracting COVID-19 during the current outbreak, and avoiding sharing of utensils. Odds Ratios (ORs) with 95\% confidence intervals (95\% CIs) were calculated to measure the strength of association. A $P$ value $<0.05$ was considered significant in the analysis.

\section{Results}

Of the 845 women who were enrolled in the assessment, we have reported that 253 women were screened positive for PPD with EPDS at a cut-off point of 10, thus resulting in a prevalence of $30.0 \%$. The number of women who had mild, moderate and severe PPD was 125 (14.8\%), 91(10.8\%), 37(4.4\%) respectively.

Of all the respondents, $42.0 \%$ were aged between 25 and 29 years. More than three-quarters $(79.7 \%)$ of the participants had senior high school or college level education. $73.1 \%$ of the participants were unmarried. $47.2 \%$ of participants reported annual household income of 15 , 000-19,999 dollars. Distribution by place of household registration showed that $52.1 \%$ of the participants were immigrants.

The association between socio-demographic characteristics and PPD was presented in Table 1. Immigrant women were significantly more likely to report PPD compared with their local counterparts.

Analysis of obstetric data, physical symptoms within the past 14 days and probable PPD was shown in Table 2 . Women who reported persistent fever were significantly more likely to develop PPD.

For social profiles, Table 3 showed lower social support was significantly associated with the development of PPD.

Table 1 Socio-demographic features of women with PPD

\begin{tabular}{|c|c|c|c|c|c|c|}
\hline \multirow[t]{2}{*}{ Factors } & \multicolumn{2}{|c|}{ EPDS < 10 (592) } & \multicolumn{2}{|c|}{ EPDS $\geq 10(253)$} & \multirow[t]{2}{*}{$x^{2}$} & \multirow[t]{2}{*}{$P$} \\
\hline & $\mathrm{n}$ & $\%$ & $\mathrm{n}$ & $\%$ & & \\
\hline Age & & & & & 0.153 & 0.985 \\
\hline$\leq 24$ & 95 & 16.0 & 41 & 16.2 & & \\
\hline $25 \sim 29$ & 248 & 41.9 & 107 & 42.3 & & \\
\hline $30 \sim 34$ & 161 & 27.2 & 70 & 27.7 & & \\
\hline$\geq 35$ & 88 & 14.9 & 35 & 13.8 & & \\
\hline Educational level & & & & & 0.054 & 0.973 \\
\hline Junior high school or less & 121 & 20.4 & 50 & 19.8 & & \\
\hline Senior high school & 203 & 34.3 & 88 & 34.8 & & \\
\hline College or more & 268 & 45.3 & 115 & 45.4 & & \\
\hline Employment & & & & & 0.264 & 0.612 \\
\hline Yes & 436 & 73.6 & 182 & 71.9 & & \\
\hline No & 156 & 26.4 & 71 & 28.1 & & \\
\hline Annual household income & & & & & 0.240 & 0.971 \\
\hline$\$ 10,000 \sim 14,999$ & 141 & 23.8 & 58 & 22.9 & & \\
\hline$\$ 15,000 \sim 19,999$ & 278 & 47.0 & 121 & 47.8 & & \\
\hline$\$ 20,000 \sim 24,999$ & 122 & 20.6 & 54 & 21.3 & & \\
\hline$\geq \$ 25,000$ & 51 & 8.6 & 20 & 7.9 & & \\
\hline Household registration in Guangzhou & & & & & 4.597 & 0.035 \\
\hline Yes & 298 & 50.3 & 107 & 42.3 & & \\
\hline No & 294 & 49.7 & 146 & 57.7 & & \\
\hline
\end{tabular}


Table 2 Obstetric data and physical symptoms of women with PPD

\begin{tabular}{|c|c|c|c|c|c|c|}
\hline \multirow[t]{2}{*}{ Factors } & \multicolumn{2}{|c|}{ EPDS < $10(592)$} & \multicolumn{2}{|c|}{ EPDS $\geq 10(253)$} & \multirow[t]{2}{*}{$x^{2}$} & \multirow[t]{2}{*}{$P$} \\
\hline & $n$ & $\%$ & $n$ & $\%$ & & \\
\hline Parity & & & & & 0.000 & 1.000 \\
\hline 1 & 278 & 46.9 & 119 & 47.0 & & \\
\hline$\geq 2$ & 314 & 53.1 & 134 & 53.0 & & \\
\hline Mode of delivery & & & & & 0.070 & 0.817 \\
\hline Vaginal & 364 & 61.5 & 158 & 62.5 & & \\
\hline Caesarean & 228 & 38.4 & 95 & 37.5 & & \\
\hline Pregnancy related disease & & & & & 0.212 & 0.632 \\
\hline Yes & 109 & 18.4 & 50 & 19.8 & & \\
\hline No & 483 & 81.6 & 203 & 80.2 & & \\
\hline Delivery related disease & & & & & 0.351 & 0.607 \\
\hline Yes & 91 & 15.4 & 43 & 17.0 & & \\
\hline No & 501 & 84.6 & 210 & 83.0 & & \\
\hline Persistent fever $\left(>37.4^{\circ} \mathrm{C}\right.$ for at least 1 day $)$ & & & & & 709.1 & 0.000 \\
\hline Yes & 18 & 3.0 & 241 & 95.3 & & \\
\hline No & 574 & 97.0 & 12 & 4.7 & & \\
\hline Cough & & & & & 0.025 & 0.867 \\
\hline Yes & 163 & 27.5 & 71 & 28.1 & & \\
\hline No & 429 & 72.5 & 182 & 71.9 & & \\
\hline Sore throat & & & & & 0.072 & 0.806 \\
\hline Yes & 408 & 68.9 & 172 & 68.0 & & \\
\hline No & 184 & 31.1 & 81 & 32.0 & & \\
\hline Persistent fever and cough or difficulty in breathing & & & & & 1.388 & 0.235 \\
\hline Yes & 36 & 6.1 & 21 & 8.3 & & \\
\hline No & 556 & 93.9 & 232 & 91.7 & & \\
\hline
\end{tabular}

Table 3 Social profiles of women with PPD

\begin{tabular}{|c|c|c|c|c|c|c|}
\hline \multirow[t]{2}{*}{ Factors } & \multicolumn{2}{|c|}{ EPDS < 10 (592) } & \multicolumn{2}{|c|}{ EPDS $\geq 10(253)$} & \multirow[t]{2}{*}{$x^{2} / t$} & \multirow[t]{2}{*}{$P$} \\
\hline & $\mathbf{n}$ & $\%$ & $\mathbf{n}$ & $\%$ & & \\
\hline Perceived family income sufficiency & & & & & 0.066 & 0.967 \\
\hline Not enough & 232 & 39.2 & 100 & 39.5 & & \\
\hline Just enough & 318 & 53.7 & 134 & 53.0 & & \\
\hline More than enough & 42 & 7.1 & 19 & 7.5 & & \\
\hline Family socio-economic status & & & & & 0.187 & 0.911 \\
\hline Low & 108 & 18.2 & 45 & 17.8 & & \\
\hline Middle & 264 & 44.6 & 110 & 43.5 & & \\
\hline High & 220 & 37.2 & 98 & 38.7 & & \\
\hline Social support & $41.03 \pm 6.78$ & & $38.70 \pm 9.16$ & & -18.004 & 0.000 \\
\hline Marital relationship & & & & & 0.271 & 0.873 \\
\hline Poor & 89 & 15.0 & 36 & 14.2 & & \\
\hline Moderate & 367 & 62.0 & 155 & 61.3 & & \\
\hline Satisfying & 136 & 23.0 & 62 & 24.5 & & \\
\hline
\end{tabular}


Table 4 represented the relationship between concerns about COVID-19 and PPD. Variables were not associated with PPD, with the exception of concerning on contracting COVID-19 during the current outbreak which was significantly associated with PPD.

Regarding the precautionary measures adopted by the respondents, avoiding the sharing of utensils (e.g, chopsticks) during meals was significantly associated with the lower rates of PPD (Table 5).

Table 6 showed the factors associated with PPD during COVID-19 pandemic in the study site. Immigrant women were 3.1 times significantly more likely to develop PPD compared to local women (OR $=3.135,95 \%$ CI: 2.759 3.428). In relation to physical symptoms, women who reported persistent fever were 2.1 times significantly more likely to develop PPD compared to women who had no fever $(\mathrm{OR}=2.084,95 \%$ CI: 1.737 2.539). Similarly, women who had lower social support were at greater risk of PPD $(\mathrm{OR}=3.478,95 \% \mathrm{CI}$ : $2.259 \sim 3.701)$. In relation to concerns about COVID19 , women who perceived higher likelihood of contracting COVID-19 during the current outbreak were 3.3 times significantly more likely to develop PPD compared to women who perceived their likelihood of contraction was low $(\mathrm{OR}=3.276,95 \% \mathrm{CI}: 2.611 \sim$ 3.589). The likelihood of PPD was also varied by their dining customs. Women who preferred to using serving utensils (e.g, chopsticks) during meals were 37\% significantly less likely to develop PPD compared to those who used sharing utensils $(\mathrm{OR}=0.672,95 \% \mathrm{CI}$ : $0.251 \sim 0.907)$.

\section{Discussion}

To our knowledge, this study was among one of the first studies with respect to the psychological responses of the delivery women in mainland China. The prevalence rate of PPD was as high as $30.0 \%$. The present figure was higher than the prevalence of PPD reported in other studies carried out in China using the EPDS scale [1719]. For example, in Hebei province of north China, $20.3 \%$ of women had elevated levels of postpartum depressive symptoms [17]. In Shanghai of east China, the estimated prevalence of PPD 6 weeks after delivery was $11.8 \%$ [18]. In Guangzhou of south China, the rate of PPD was $27.4 \%$ [19]. However, our result is consistent with reports in Asian countries which indicated the prevalence of PPD ranged from 3.5 to $63.3 \%$ [20]. Another cross-sectional study in Brazil also found a similar prevalence of PPD (27.9\%) among low income women [10]. Higher rates of PPD in this study may be explained by two evident differences between other studies and the current one. First, the present data were obtained during the COVID-19 pandemic. Although the COVID-19 outbreak in Guangzhou may not be regarded as severe, the number of imported cases is increasing during the time the study was conducted. According to Behavioral Immune System theory, people are likely to develop negative emotions and avoidant behaviors when faced with public health emergencies [11]. The uncertainty and unpredictability of COVID-19 may cause cognitive dissonance and insecurity, thus providing a feeling of mental discomfort. In addition, with the closure of schools and business as well as social-distancing regulations, negative

Table 4 Association between concerns about COVID-19 and PPD

\begin{tabular}{|c|c|c|c|c|c|c|}
\hline \multirow[t]{2}{*}{ Factors } & \multicolumn{2}{|c|}{ EPDS $<10(592)$} & \multicolumn{2}{|c|}{ EPDS $\geq 10(253)$} & \multirow[t]{2}{*}{$x^{2}$} & \multirow[t]{2}{*}{$P$} \\
\hline & $\bar{n}$ & $\%$ & $\mathrm{n}$ & $\%$ & & \\
\hline Level of confidence in doctor's ability to diagnose or recognize & & & & & 1.129 & 0.569 \\
\hline High & 314 & 53.1 & 136 & 53.8 & & \\
\hline Middle & 228 & 38.5 & 101 & 39.9 & & \\
\hline Low & 50 & 8.4 & 16 & 6.3 & & \\
\hline Likelihood of contracting COVID-19 during the current outbreak & & & & & 104.1 & 0.000 \\
\hline High & 105 & 17.7 & 112 & 44.3 & & \\
\hline Middle & 174 & 29.4 & 96 & 37.9 & & \\
\hline Low & 313 & 52.9 & 45 & 17.8 & & \\
\hline Concerns about other family members contracting COVID-19 & & & & & 0.103 & 0.960 \\
\hline High & 211 & 35.6 & 90 & 35.6 & & \\
\hline Middle & 200 & 33.8 & 88 & 34.8 & & \\
\hline Low & 181 & 30.6 & 75 & 29.6 & & \\
\hline Likelihood of surviving if infected with COVID-19 & & & & & 0.438 & 0.803 \\
\hline High & 479 & 80.9 & 206 & 81.4 & & \\
\hline Middle & 94 & 15.9 & 41 & 16.2 & & \\
\hline Low & 19 & 3.2 & 6 & 2.4 & & \\
\hline
\end{tabular}


Table 5 Association between precautionary measures and PPD

\begin{tabular}{|c|c|c|c|c|c|c|}
\hline \multirow[t]{2}{*}{ Factors } & \multicolumn{2}{|c|}{ EPDS < $10(592)$} & \multicolumn{2}{|c|}{ EPDS $\geq 10$ (253) } & \multirow[t]{2}{*}{$x^{2}$} & \multirow[t]{2}{*}{$P$} \\
\hline & $\mathrm{n}$ & $\%$ & $\mathbf{n}$ & $\%$ & & \\
\hline Covering mouth when coughing or sneezing & & & & & 0.501 & 0.778 \\
\hline Always & 409 & 69.1 & 178 & 70.4 & & \\
\hline Sometime & 140 & 23.6 & 60 & 23.7 & & \\
\hline Occasionally & 43 & 7.3 & 15 & 5.9 & & \\
\hline Washing hands with soap & & & & & 0.255 & 0.881 \\
\hline Always & 396 & 66.9 & 170 & 67.2 & & \\
\hline Sometime & 168 & 28.4 & 73 & 28.8 & & \\
\hline Occasionally & 28 & 4.7 & 10 & 4.0 & & \\
\hline Wearing a mask regardless of the presence or absence of symptoms & & & & & 0.089 & 0.967 \\
\hline Always & 486 & 82.1 & 209 & 82.6 & & \\
\hline Sometime & 95 & 16.0 & 40 & 15.8 & & \\
\hline Occasionally & 11 & 1.9 & 4 & 1.6 & & \\
\hline Avoiding sharing of utensils (e.g, chopsticks) during meals & & & & & 145.3 & 0.000 \\
\hline Always & 318 & 53.7 & 41 & 16.2 & & \\
\hline Sometime & 173 & 29.2 & 75 & 29.6 & & \\
\hline Occasionally & 101 & 17.1 & 137 & 54.2 & & \\
\hline Average number of hours staying at home per day to avoid COVID-19 & & & & & 0.399 & 0.819 \\
\hline $20 \sim 24 \mathrm{~h}$ & 189 & 31.9 & 82 & 32.4 & & \\
\hline $10 \sim 19 \mathrm{~h}$ & 293 & 49.5 & 120 & 47.4 & & \\
\hline $0 \sim 9 \mathrm{~h}$ & 110 & 18.6 & 51 & 20.2 & & \\
\hline
\end{tabular}

Table 6 Multivariate logistic regression analysis of impact factor of PPD

\begin{tabular}{|c|c|c|c|c|c|c|}
\hline Covariates & $B$ & S.E & Wald & $P$ & OR & $95 \% \mathrm{Cl}$ \\
\hline \multicolumn{7}{|c|}{ Household registration place in Guangzhou } \\
\hline Yes & - & - & 21.049 & - & - & - \\
\hline No & 0.067 & 0.236 & 28.730 & 0.000 & 3.135 & $2.759 \sim 3.428$ \\
\hline \multicolumn{7}{|c|}{ Persistent fever $\left(>37.4^{\circ} \mathrm{C}\right.$ for at least 1 day) } \\
\hline Yes & 0.018 & 0.225 & 11.341 & 0.000 & 2.084 & $1.737 \sim 2.539$ \\
\hline No & - & - & 8.709 & - & - & - \\
\hline Social support & 0.615 & 0.349 & 35.012 & 0.000 & 3.478 & $2.259 \sim 3.701$ \\
\hline \multicolumn{7}{|c|}{ Likelihood of contracting COVID-19 during the current outbreak } \\
\hline High & 0.541 & 0.133 & 21.085 & 0.000 & 3.276 & $2.611 \sim 3.589$ \\
\hline Middle & 0.677 & 0.435 & 18.018 & 0.721 & 1.549 & $0.608 \sim 2.133$ \\
\hline Low & - & - & 26.547 & - & - & - \\
\hline \multicolumn{7}{|c|}{ Avoiding sharing of utensils (e.g, chopsticks) during meals } \\
\hline Always & 0.097 & 0.169 & 15.044 & 0.013 & 0.627 & $0.251 \sim 0.907$ \\
\hline Sometime & 0.008 & 0.136 & 29.820 & 0.156 & 1.349 & $0.886 \sim 1.835$ \\
\hline Occasionally & - & - & 31.472 & - & - & - \\
\hline
\end{tabular}

emotions experienced by individuals are compounded. Therefore, these COVID-19 related factors have helped to add the stressful impact on women's mental health. Second, the present study was entirely drawn from Guangzhou, one of the most affluent metropolis in south China. As Guangzhou is one of the major air transportation hubs with more than 130 international flights connecting main countries in the world, the potential impact of global COVID-19 outbreak is high. Moreover, with the lockdown eased gradually to ensure smooth resumption of work and production, internal migrants who were originally from the large poor and rural areas in the western and central inland provinces migrated to the southern developed regions, such as Guangzhou for better job opportunities and income. The convenience of long-distance travel could increase the incidence of local cases through respiratory droplets (e.g., from exhalation sneeze) and contact routes [21]. And the possibility of transmission by asymptomatic carriers could further enhance it's spread [21]. Such occurrences of both imported cases and domestically transmitted cases have significant potential for psychological contagion, resulting in widespread fear, helplessness, and a variety of adverse mental health outcomes [7].

The findings of this study showed that immigrant women were significantly more likely to develop PPD 
compared to local registered women, which was consistent with the findings of previous studies that immigrant women were at increased risk of depression perinatally [22]. Due to long-standing household registration policy in China, internal migrants do not have the same rights and benefits as local residents in a variety of areas, such as healthcare, social services, education and employment. We hypothesized social exclusion resulting from this policy as well as other economic and cultural factors have an impact on mental health of immigrants. We also reported a strong association between social support and PPD which was consistent with a previous study [19]. One possible reason is that during the pandemic, the pace of the whole society is slowed down. This could have been created more opportunities and time for family member to support and care for each other. In addition, communication with community members and friends was increased because people were asked to stay at home instead of going to public places. These positive impacts may have helped women cope with the challenges surrounding the postpartum period.

In addition, we explored the relationship between mental health and physical symptoms as well as concerns about COVID-19 among delivery women during the pandemic. The presence of a persistent fever was significantly associated with PPD. Similarly, a higher perceived likelihood of contracting COVID-19 during the current outbreak was significantly associated with PPD. Amid this moment, women were bombarded with various discomforting network information about COVID19 , including clinical signs, routes of transmission, medicines or vaccines, et al. After presentation to the clinic with a fever, they may be sent home, hospitalized for further observation, or quarantined. Some evidences suggest that up-to-date and accurate information during the pandemic is responsible for lower levels of stress, anxiety and depression [7]. Moreover, higher satisfaction with the health information received by the whole population is contributing to the reduced impact of rumors and this may avoid adverse psychological reactions.

Also, our findings suggest that precautionary measures adopted to prevent the spread of COVID-19 have had a positive psychological effect. Women who had avoided the sharing of utensils (e.g, chopsticks) during meals were significantly less likely to develop PPD. There has been no evidence to suggest the reason for the difference, but saliva is one of the most common ways for food-borne diseases to spread. Communal eating habits have been a part of Chinese culture for centuries. Chinese people prefer to using chopsticks to pick up food commonly shared in the table during meal times to show their respect. The experiences of the SARS-COV epidemic in 2013 may have changed the perception of the general public towards precautionary measures.
Many cities in China have already launched initiatives to order separate meals. As this healthy habit is related to people's health and safety during the pandemic, it's not unexpected that avoidance of sharing utensils during meals is significantly associated with less psychological impact on women.

Our findings will provide vital guidance for health care professionals to tackle mental health issues among delivery women during a pandemic. First, health authorities need to identify high-risk groups such as immigrants for early intervention. Second, accurate and up-to-date health information during the pandemic needs to be provided in order to alleviate the concern and reduce the impact of rumors. Third, government and health authorities need to expand public awareness of healthy lifestyle.

This study has several limitations. First, a crosssectional study did not allow for establishing causal relationships between PPD and the factors associated with it. Second, a self-reported scale was employed to define PPD instead of clinician administered structured interview. Participants might have provided responses they feel socially desirable. Third, the short time frame might not allow us to observe it's long-term impacts on mental health among delivery women.

\section{Conclusion}

During the COVID-19 pandemic in China, about onethird of the women reported PPD. Immigrants, persistent fever, lower social support and higher level of concerning about contracting COVID-19 were associated with higher risk of PPD. Certain precautionary measures were associated with a lower risk of PPD. Since the COVID-19 is going on, our findings can be used to formulate psychological interventions to minimize depression and improve psychological resilience among women following childbirth.

\section{Abbreviations \\ COVID-19: 2019 Coronavirus Disease; PPD: Postpartum depression; EPDS: Edinburgh Postnatal Depression Scale; WHO: World Health} Organization; SARS: Severe Acute Respiratory Syndrome

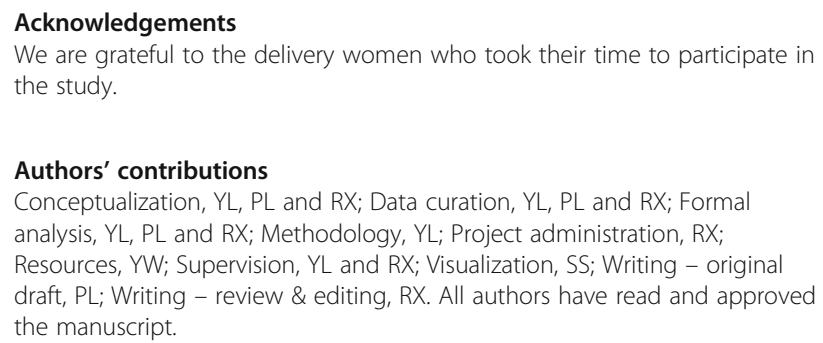

Authors' contributions

Conceptualization, YL, PL and RX; Data curation, YL, PL and RX; Formal analysis, YL, PL and RX; Methodology, YL; Project administration, RX; Resources, YW; Supervision, YL and RX; Visualization, SS; Writing - original draft, PL; Writing - review \& editing, RX. All authors have read and approved the manuscript.

Funding

Not applicable. 


\section{Availability of data and materials}

The datasets used and/or analyzed during the current study are available from the corresponding author on reasonable request.

\section{Ethics approval and consent to participate}

Ethical approval was obtained from the Research Ethics Board of Southern Medical University on March 10th, 2020. Participants were provided with online information sheet and asked to sign a consent form prior to the investigations being undertaken.

\section{Consent for publication}

Not applicable.

\section{Competing interests}

The authors declare that they have no competing interests.

Received: 7 May 2020 Accepted: 17 November 2020

Published online: 25 November 2020

\section{References}

1. Wang C, Horby PW, Hayden FG, Gao GF. A novel coronavirus outbreak of global health concern. Lancet. 2020;395:470-3.

2. Nishiura H, Jung SM, Linton NM, Kinoshita R, Yang Y, Hayashi K, et al. The extent of transmission of novel coronavirus in Wuhan, China, 2020. J Clin Med. 2020:9(2):330.

3. Mahase E. China coronavirus: WHO declares international emergency as death toll exceeds 200. BMJ. 2020:368:m408.

4. National Health Commission of People's Republic of China. National Health Commission's Briefing on the Pneumonia Epidemic Situation. Available online: http://www.nhc.gov.cn/xcs/yqfkdt/gzbd_index.shtml. Accessed 19 Mar 2020

5. Lu YC, Shu BC, Chang YY, Lung FW. The mental health of hospital workers dealing with severe acute respiratory syndrome. Psychother Psychosom. 2006; $75: 370-5$

6. Rubin GJ, Potts HW, Michie S. The impact of communications about swine flu (influenza a H1N1v) on public responses to the outbreak: results from 36 national telephone surveys in the UK. Health Technol Assess. 2010;14(34): 183-266.

7. Wang C, Pan R, Wan X, Tan Y, Xu L, Ho CS, Ho RC. Immediate psychological responses and associated factors during the initial stage of the 2019 coronavirus disease (COVID-19) epidemic among the general population in China. Int J Environ Res Public Health. 2020;17(5):1729.

8. Yim IS, Tanner Stapleton LR, Guardino CM, Hahn-Holbrook J, Dunkel SC Biological and psychosocial predictors of postpartum depression: systemic review and call for integration. Annu Rev Clin Psychol. 2015;11:99-137.

9. Abdollahi F, Zarghami M. Effect of postpartum depression on women's mental and physical health four years after childbirth. East Mediterr Health J. 2018;24:1002-9.

10. Faisal-Cury A, Menezes PR, d'Oliveira AF, Schraiber LB, Lopes CS. Temporal relationship between intimate partner violence and postpartum depression in a sample of low income women. Matern Child Health J. 2013;17(7):1297303.

11. Schaller M, Murray DR, Bangerter A. Implications of the behavioral immune system for social behavior and human health in the modern world. Philos Trans Biol Sci. 2015;370(1669):1-10.

12. Guangdong statistical information: The data of the Sixth National Population Census of Guangzhou city. http://www.gzstats.gov.cn/pchb/ rkpc6/. Accessed 4 Jan 2020.

13. Gaskin CJ, Happell B. Power, effects, confidence, and significance: an investigation of statistical practices in nursing research. Int J Nurs Stud. 2014;51(5):795-806.

14. Lee DT, Yip SK, Chiu HF, Leung TY, Chan KP, Chau IO, et al. Detecting postnatal depression in Chinese women. Validation of the Chinese version of the Edinburg postnatal depression scale. Br J Psychiatry. 1998;172:433-7.

15. Uher R, Farmer A, Maier W, Rietchel M, Hauser J, Marusic A, et al. Measuring depression:comparison and intergration of three scales in the GENDEP study. Psychol Med. 2008:38(2):289-300

16. Chen TL, Tai CJ, Chu YR, Han KC, Lin KC, Chien LY. Cultural factors and social support related to breastfeeding among immigrant mothers in Taipei City, Taiwan. J Hum Lact. 2011;27(1):41-8.
17. Armony-Sivan R, Shao J, Zhao G, Xu G, Zhou M, Zhan J, et al. No relationship between maternal iron status and postpartum depression in two samples in China. J Pregnancy. 2012;2012:521431.

18. Ding G, Niu L, Vinturache A, Zhang J, Lu M, Gao Y, et al. "Doing the month" and postpartum depression among Chinese women: a Shanghai prospective cohort study. Women Birth. 2020;33(2):e151-8.

19. Deng AW, Xiong RB, Jiang TT, Luo YP, Chen WZ. Prevalence and risk factors of postpartum depression in a population-based sample of women in Tangxia community, Guangzhou. Asian Pac J Trop Med. 2014;7(3):244-9.

20. Klainin P, Arthur DG. Postpartum depression in Asian culture: a literature review. Int J Nurs Stud. 2009:16(10):1355-73.

21. Chen LD. Effect of ambient temperature and humidity on droplet lifetime-a perspective of exhalation sneeze droplets with COVID-19 virus transmission. Int J Hyg Environ Health. 2020;229:113568.

22. Chen J, Cross WM, Plummer V, Lam L, Tang S. A systematic review of prevalence and risk factors of postpartum depression in Chinese immigrant women. Women Birth. 2019;32:487-92.

\section{Publisher's Note}

Springer Nature remains neutral with regard to jurisdictional claims in published maps and institutional affiliations.

Ready to submit your research? Choose BMC and benefit from:

- fast, convenient online submission

- thorough peer review by experienced researchers in your field

- rapid publication on acceptance

- support for research data, including large and complex data types

- gold Open Access which fosters wider collaboration and increased citations

- maximum visibility for your research: over $100 \mathrm{M}$ website views per year

At $\mathrm{BMC}$, research is always in progress.

Learn more biomedcentral.com/submissions 